Journal Article

\title{
Comparative study on foaming and emulsifying properties of different beta-lactoglobulin aggregates
}

Hu, J., Yang, J., Xu, Y., Zhang, K., Nishinari, K., Phillips, G.O., Fang, Y

This article is published by Royal Society of Chemistry and is subject to a period of 12 months' embargo. The definitive version of this article is available at:

https://pubs.rsc.org/en/content/articlelanding/2019/fo/c9fo00940j/unauth\#!divAbstract

\section{Recommended citation:}

Hu, J., Yang, J., Xu, Y., Zhang, K., Nishinari, K., Phillips, G.O., Fang, Y (2019) 'Comparative study on foaming and emulsifying properties of different beta-lactoglobulin aggregates', Food \& Function, 10, 5922-5930. Available online 27 Aug 2019. doi: 10.1039/C9FO00940J 


\title{
Comparative study on foaming and emulsifying properties of different beta-lactoglobulin aggregates
}

\author{
Jing Hu, ${ }^{a, c}$ Jixin Yang, ${ }^{b}$ Yao Xu, ${ }^{c}$ Ke Zhang, ${ }^{c}$ Katsuyoshi Nishinari, ${ }^{c}$ Glyn O. Phillips ${ }^{c}$ and Yapeng Fang $*, a, c$ \\ *Corresponding authors \\ a Department of Food Science and Technology, School of Agriculture and Biology, Shanghai Jiao Tong \\ University, Shanghai 200240, China \\ E-mail:ypfang@sjtu.edu.cn \\ Fax: +86-(0)-21-34208547 \\ Tel: +86-(0)-21-34208547 \\ ${ }^{\mathrm{b}}$ Faculty of Arts, Science and Technology, Wrexham Glyndwr University, Mold Road, Wrexham, UK \\ ' Glyn O. Phillips Hydrocolloid Research Centre at HUT, School of Food and Biological Engineering, \\ Hubei University of Technology, Wuhan 430068, China
}

\begin{abstract}
Different conditions in food processing lead to different aggregates of protein. $\beta$-Lactoglobulin nanoparticles (BLGNPs) and fibrils (BLGFs) were prepared by adjusting $\mathrm{pH}$ and temperature, and thereby their foaming and emulsifying properties were compared to native globular $\beta$-lactoglobulin (NGBLG) at pH 7.0 and pH 4.0. A foam analyser, a microparticle size analyser, an interfacial rheometer and an atomic force microscope (AFM) were used to characterise foaming/emulsifying functionalities and interfacial microstructures/mechanical properties. The foam and emulsion stabilities were assessed by measuring the decay of foam height and the variation of emulsion droplet size, and both were found to be in the order of BLGFs > NGBLG > BLGNPs. Foams were more stable at $\mathrm{pH} 4.0$ while emulsions were more stable at $\mathrm{pH}$ 7.0. Surface dilatational modulus (E) of NGBLG and its aggregates at $\mathrm{pH} 4.0$ was greater than that at $\mathrm{pH} 7.0$, with BLGFs showing the highest value of $E$ and thus the highest resistance to membrane damage. The emulsion prepared with NGBLG and its aggregates had more negative charges at $\mathrm{pH} 7.0$ than at $\mathrm{pH}$ 4.0. The foaming stability seemed to be more controlled by interfacial elasticity while the emulsion stability was more determined by surface charges. AFManalysis demonstrated different microstructures at the airwater interface between $\mathrm{pH} 4.0$ and 7.0 and among the different protein aggregates, which could well explain their foaming and emulsifying properties.
\end{abstract}


Introduction

Globular proteins are amphiphilic macromolecules that are widely used as foaming and emulsifying agents in the food industry. This is primarily due to their ability to unfold and adsorb at the interface, as well as the ability to form viscoelastic interfacial films through intermolecular interactions. ${ }^{1-4}$ In aqueous solutions, globular proteins are usually present in the form of monomers or small oligomers, and they are stabilised by electrostatic repulsion. ${ }^{5}$ Natural globular $\beta$-lactoglobulin (NGBLG) is a sphere-like protein that is abundantly contained in milk and has received much attention for its nutritional and functional properties in the food industry. ${ }^{6}$ Typically, NGBLG is in the form of a dimer consisting of two monomeric subunits joined by non-covalent bonds. In its "monomeric" form, it has 162 amino acid residues with 8 antiparallel sheets, 1 R-helix strand and a molar mass of $18.3 \mathrm{kDa} .{ }^{7,8}$ By heating or pressurising, the protein will be denatured and the natural conformation of the protein will change. ${ }^{9,10}$ Heating above the denaturation temperature results in partial unfolding of the globular protein, thereby exposing groups initially buried within its structure. This may eventually lead to aggregation between different molecules through hydrogen bonding and hydrophobic interactions. The presence of cysteine in the polypeptide chain leads to formation of disulfide bonds which makes aggregation generally irreversible. ${ }^{5}$

Parameters such as $\mathrm{pH}$, protein concentration, heating time, type and concentration of salts added determine the size and structure of the aggregates formed. There are several globular proteins that have a high tendency to form amyloid fibrils or nanoparticl es by adjusting $\mathrm{pH}$, concentration and temperature. When whey proteins were heated at $80^{\circ} \mathrm{C}$ and $\mathrm{pH} 2.0$ for several hours, they were first hydrolysed into peptides, and then some of the peptides self-assembled into fibrils. ${ }^{11}$ It has been found that heating whey protein to form aggregates improved its foaming stability and increased its foaming capacity due to the presence of unconverted monomers, including $\alpha$-lactalbumin and NGBLG. ${ }^{12,13}$ The effect of protein concentration on aggregation at different $\mathrm{pH}$ values (i.e. 5.8, $6.0,6.5,7.0$, and 8.0) was investigated. ${ }^{14}$ The solution was heated at $80^{\circ} \mathrm{C}$ under low ionic strength until a steady state was reached and all proteins were denatured. Size exclusion chromatography (SEC) was used to show that the solution contained monomers and small oligomers, mainly dimers and trimers, as well as different larger aggregate groups. The proportion of large aggregates increased with protein concentration. Due to the weak hydrophobicity and hydrogen bonding interaction of the monomers, NGBLG was aggregated, and the intramolecular $\beta$-sheet was converted into the intermolecular $\beta$-sheet. ${ }^{15}$ Furthermore, proteins can be converted into nanoparticles. Food protein-based nanoparticles have been attracting much attention, and they are generally considered to be safe. In addition, the production process is simple and highly reproducible, and chemical crosslinking to better control the particle size distribution is not required during preparation. ${ }^{16}$

The foaming properties of proteins have been extensively studied. Foam is a dispersion of bubbles in a liquid, stabilised by amphiphilic molecules. ${ }^{17}$ Proteins such as egg white, whey protein and soy protein are the most widely used foaming agents in the food industry. ${ }^{18,19}$ Foams are essential components of various foods, including whipped cream, marshmallows, smoothies, desserts, meringues and ice cream. The stability of foams is mainly determined by the properties of the foam films, which separates the foams, and many studies have focused on the properties of proteins in the interface of foam films. ${ }^{3,20,21}$ Proteins stabilise the foam by strongly adsorbing to the air-water interface to form viscoelastic film, and the layer leads to a protein network with high viscosity. ${ }^{22}$ Some studies have reported improvement in emulsification and foaming properties of NGBLG and WPI (whey protein isolate) by heat treatment. ${ }^{23,24}$ Others have studied the effect of protein aggregates on the foaming properties of NGBLG and found that protein aggregates themselves did not improve foaming properties, but they had better foam stability in the presence of nonaggregated proteins, which appear to be necessary to produce a stable foam..$^{25} \mathrm{However}$, high protein concentrations were usually required in food applications to stabilise foams, which increased 
production costs. ${ }^{26}$ Jung et al. found that thermally induced transformation of NGBLG into BLGFs could improve the stability of foam, because the BLGFs could more rapidly adsorb to the air-water interface compared with NGBLG, and form a more elastic network at the foam interface. ${ }^{27}$ It was also found that $\mathrm{pH}$ had an effect on the foaming properties of the BLGFs. Foam stability increased as the $\mathrm{pH}$ increased from 2 to 8 , and the BLGFs provided the optimum foam stability when the $\mathrm{pH}$ approached the isoelectric point. ${ }^{28}$ The mechanisms of foam instability include liquid drainage caused by gravity and liquid transfer from the inter-bubble lamella to the plateau border, and foam collapse caused by lamellar rupture and disproportionation. . $^{29,30}$

Many researchers have studied the functional properties of NGBLG, including gels, emulsions, interfaces, foams, etc. Not only foam, but also emulsions can be efficiently produced and stabilised by proteins and their aggregates. In the food industry, emulsions are obtained by shearing and homogenising in the presence of an emulsifier. ${ }^{31}$ Emulsions are widely used in the formulation of foods, cosmetics and pharmaceuticals, and NGBLG is a good emulsifier. For instance, researchers used NGBLG in oil-in-water emulsions for formulating dermatological drugs. ${ }^{32}$ Proteins are not as effective in reducing interfacial tension as synthetic emulsifiers, but they result in more thermodynamically and kinetically stable emulsions. The formation and stability of emulsions are highly dependent on the interfacial properties of proteins. ${ }^{33,34} \mathrm{In}$ fact, they form a viscoelastic adsorption layer on the oil droplets and are capable of creating a repulsive and electrostatic interaction between the droplets. ${ }^{35}$ It was found that BLGFs showed significantly higher elasticity at the oil-water interface compared to pure proteins, and had better emulsifying activity and emulsion stability. ${ }^{36}$ Knudsen et al. heated NGBLG at pH 7.0 for different time to prepare aggregates with a radius of gyration in the range of $25-40 \mathrm{~nm}$. The viscosity and elastic modulus of the emulsion prepared with the aggregates increased significantly, indicating an increased oil droplet interactions. ${ }^{37}$

There have been some studies dealing with the foaming or emulsifying properties of protein nanoparticles or fibrils prepared from native proteins. ${ }^{22,27}$ However, to the best our knowledge, no direct and systematic comparison so far has been made between native, nanoparticulate and fibrillar proteins, under comparable conditions and in terms of both air-water and oil-water interfacial properties. It is generally found that the aggregation of proteins induced by heating or pressurising is irreversible, and the size of aggregates is related to protein concentration. ${ }^{5}$ In this study, NGBLG, which is the main ingredient of whey protein, was selected for comparative studies of foaming and emulsifying properties before and after aggregation and at different $\mathrm{pHs}$.

\section{Materials and methods}

\section{Materials}

Natural globular $\beta$-lactoglobulin (NGBLG) was extracted from raw milk. A high-purity protein (powder dry weight containing $97.32 \%$ protein) was obtained through a series of procedures, ${ }^{38,39}$ which was compared with NGBLG from Davisco Foods International (using SDS-PAGE, HPLC, etc., data not shown) for quality assurance.

All other chemicals were of analytical grade. Ultrapure water $(18.25 \mathrm{M} \Omega \mathrm{cm})$ was obtained from a Milli-Q system and used for sample preparations and experiments. 


\section{Samples preparation}

Preparation of $\beta$-lactoglobul in nanoparticles (BLGNPs). NGBLG solution $\left(10 \mathrm{mg} \mathrm{mL}^{-1}\right)$ with $\mathrm{pH} 5.8$ was heated in an $85^{\circ} \mathrm{C}$ water bath for $15 \mathrm{~min}$ and cooled in ice water for $20 \mathrm{~min}$. The solution was dialyzed against $\mathrm{pH} 5.8$ water at $4{ }^{\circ} \mathrm{C}$ for $72 \mathrm{~h}(\mathrm{MWCO}=50 \mathrm{kDa})$. Finally, the sample was freeze dried to obtain BLGNPs.

Preparation of $\beta$-lactoglobul in fibrils (BLGFs). NGBLG solution ( $20 \mathrm{mg} \mathrm{mL}^{-1}$ ) with $\mathrm{pH} 2.0$ was heated in an $80^{\circ} \mathrm{C}$ water bath for $16 \mathrm{~h}$ and cooled in ice water for $20 \mathrm{~min}$. The solution was dialyzed against $\mathrm{pH}$ 2.0 water at $4{ }^{\circ} \mathrm{C}$ for $72 \mathrm{~h}(\mathrm{MWCO}=100 \mathrm{kDa}$ ). Finally, the sample was freeze-dried to obtain BLGFs.

\section{Transmission electron microscopy (TEM)}

The morphologies of NGBLG, BLGNPs, and BLGFs ( $2 \mathrm{~mL}$ ) were observed by TEM (JEM-2100F, JEOL, Tokyo, Japan) at a concentration of $0.5 \mathrm{mg} \mathrm{mL}^{-1}$. All the samples were deposited onto a carboncoated copper grid ( 230 meshes) and excess samples were sucked away by a micropipette. The processed samples were slowly dried for $72 \mathrm{~h}$ at $25 \pm 1{ }^{\circ} \mathrm{C}$ in a desiccator, and then negatively stained by phosphotungstic acid $\left(10 \mathrm{mg} \mathrm{mL}^{-1}\right)$ for $60 \mathrm{~s}$ for measurements. The length of BLGFs measured by TEM was analyzed using Fiber APP (http://www.fsm.ethz.ch).

\section{Size and isoelectricpoint}

The size distributions and isoelectric points of NGBLG and its aggregates were determined using a Zetasizer Nano-ZS apparatus (Malvern Instruments, Worcestershire, UK). Samples were adjusted to various $\mathrm{pHs}$ and diluted to $1 \mathrm{mg} \mathrm{mL}^{-1}$ before being loaded into cuvettes. All measurements were carried out at $25 \pm 1^{\circ} \mathrm{C}$ in triplicate.

\section{Surface hydrophobicity}

The hydrophobicity of NGBLG and its aggregates was determined by the 8-anilino-1naphthalenesulfonic acid (ANS) fluorescent probe method. 40 NGBLG and its aggregates were dissolved in buffer solutions (made of $0.1 \mathrm{M}$ citric acid and $0.2 \mathrm{M} \mathrm{Na}_{2} \mathrm{HPO}_{4}$ ) at pH 7.0 and pH 4.0. The range of sample concentrations was $0.05-1 \mathrm{mg} \mathrm{mL}^{-1} .20 \mu \mathrm{L}$ of $8 \mathrm{mmol} \mathrm{L}^{-1}$ ANS was added to each protein sample $(2 \mathrm{~mL})$. Excitation and emission wavel engths were $390 \mathrm{~nm}$ and $470 \mathrm{~nm}$, respectively, and the excitation and emission slit widths were both $5 \mathrm{~nm}$. The fluorescence intensity was measured by the fluorescence spectrophotometer (Hitachi F-7000, Japan). The initial slope of the fluorescence intensity versus concentration was calculated and reported as the surface hydrophobicity index $\left(\mathrm{S}_{0}\right)$ of NGBLG and its aggregates.

\section{Foaming properties}

The foaming properties of NGBLG and its aggregates were investigated using the KRÜSS dynamic foam analyser DFA100 (KRÜSS GmbH, Germany), which measures foam capacity and stability through foam height and its decay over time. For foaming, the compressed air was passed through a sintered porous glass frit at the bottom of a cylindrical glass vessel having a height of $250 \mathrm{~mm}$ and an inner diameter of $40 \mathrm{~mm}$. The porous glass frit (FL 4504, pores of 16-40 $\mu \mathrm{m}$, DURAN ${ }^{\circledR}$ ) was purged with pressurised air $\left(0.3 \mathrm{~L} \mathrm{~min}^{-1}\right)$, where $50 \mathrm{~mL}$ of $1 \mathrm{mg} \mathrm{mL}^{-1} \mathrm{NGBLG}$ and its aggregates solutions were foamed to a maximum height of $180 \mathrm{~mm}$. The foam generating device was connected to a computer that serves as a data acquisition and monitoring unit. The result evaluation and analysis of the entire measurement were controlled by the foam analysis software. An image of bubble size distribution per second at $80 \mathrm{~mm}$ above the frit was captured by a CCD camera. The overall foam 
stability was evaluated by the half-life of the foam $\left(t_{1 / 2}\right)$ which is defined as the time required for the foam height to decrease to the half of the initial value. The foaming capacity was evaluated by the ratio of the maximum foam volume to the volume of gas used for foaming. The experiment was carried out at $25 \pm 2{ }^{\circ} \mathrm{C}$, and repeated three times to obtain the averaged values.

\section{Emulsion preparation}

The emulsifying properties of NGBLG, BLGNPs and BLGFs were evaluated by a model oil-in-water emulsion, using medium chain triglyceride (MCT). The emulsions contained $1 \mathrm{mg} \mathrm{mL}^{-1}$ total protein in the aqueous phase and $150 \mathrm{mg} \mathrm{mL}^{-1} \mathrm{MCT}$ in the oil phase, with $0.2 \mathrm{mg} \mathrm{mL}^{-1}$ sodium azide to prevent the growth of microorganisms. NGBLG (or BLGNPs, BLGFs) solution was blended with MCT and pre-homogenisation, using a high-speed Polytron PT-MR2100 shear mixer (Kinematica Co., Lausanne, Switzerland) at $26000 \mathrm{rpm}$ for $2 \mathrm{~min}$ in an ice bath. The pre-emulsion was adjusted to $\mathrm{pH}$ 7.0 and $\mathrm{pH} 4.0$ with $\mathrm{HCl}$ and circulated twice through a high pressure homogeniser (M-110L, MFIC, US) at $75 \mathrm{MPa}$. The $\mathrm{pH}$ of the final emulsion was checked again and fine-tuned to $\mathrm{pH} 7.0 \mathrm{or} \mathrm{pH} 4.0$ if necessary. The prepared fresh emulsion was stored at $25 \pm 2{ }^{\circ} \mathrm{C}$ for 90 days.

\section{Emulsion characterization}

The Mastersizer 2000 laser particle size analyser (Malvern, UK) was used to determine the average particle size of the emulsion. Ultrapure water was used as the dispersion medium. The emulsion was gently shaken and then added dropwise to the dispersion medium until the signal met the test requirements. The refractive indexes of the dispersed phase and the continuous phase (water) were 1.45 and 1.33 , respectively. The opacity was $10-20 \%$ and the particle absorption rate was 0.001 . The pump rotation speed was $2000 \mathrm{rpm}$, and each sample was measured three times and the average value was taken. The average particle size of the emulsion is represented by $d_{32}$ and $d_{43}$ which represent the surface area weighted average and the volume weighted average, respectively, where $d_{32}$ is sensitive to the presence of small particles in the sample, and $d_{43}$ is sensitive to the presence of large particles in the sample that is used to monitor the stability of the emulsion during storage.

The BT-1600 image particle analysis system (Dandong Bettersize Instrument, China) was used to observe the microscopic morphology of the emulsion particles. The system consisted of an optical microscope (Nikon YS100), a digital CCD camera (HV2001UC), and a software for image processing and analysis. A small drop of emulsion was placed between the microscope slide and the coverslip. All the images were taken at a magnification of 10 times and calibrated against a graticule with 10 $\mu \mathrm{m}$ intervals.

\section{Surface pressure and surface dilatational rheology}

The interfacial adsorption behavior of NGBLG and its aggregates was analysed by the change of surface pressure $(\pi)$ and surface dilatational modulus (E) during the interfacial adsorption process. The hanging mode of the Tracker bubble/droplet profile analyser (Teclis, France) was selected to detect the adsorption of the sample at the air-water interface. NGBLG and its aggregates solutions were diluted to $0.1 \mathrm{mg} \mathrm{mL}^{-1}$ and adjusted to $\mathrm{pH} 7.0$ and $\mathrm{pH} 4.0$ for interface analysis. $\mathrm{A} 5 \mathrm{~mL}$ mixed dispersion was weighed into the sample cell, and the U-shaped sample needle was immersed in the aqueous phase. The sinusoidal interfacial compression and dilatation were performed by changing the droplet volume at $10 \%$ of the deformation amplitude in the linear range. The oscillation frequency and the hanging drop volume were $0.05 \mathrm{~Hz}$ and $10 \mu \mathrm{L}$, respectively. At $25 \pm 0.1^{\circ} \mathrm{C}$, the density of air and samples were $0.001185 \mathrm{~g} \mathrm{~cm}^{-3}$ and about $1.001 \mathrm{~g} \mathrm{~cm}^{-3}$, respectively. The interfacial tension between deionised water and air was $72 \pm 0.1 \mathrm{mN} \mathrm{m}^{-1}$. 


\section{Atomic force microscope (AFM) imaging}

Atomic force microscopy (Bruker AXS, Multimode8, USA) was used to observe the adsorption morphology of NGBLG and its aggregates at the air-water interface at different pHs using Peak Force Tapping mode. A silicone cantilever (Bruker, Scanasyst-air, USA) with a driving frequency of $70 \mathrm{kHz}$ and an elastic constant of $0.4 \mathrm{~N} \mathrm{~m}^{-1}$ was used for scanning. A modified Langmuir-Schaefer technique was employed to transfer interfacial structures onto mica substrate. ${ }^{41}$ The technique has been demonstrated to be able to reflect the interfacial structures without artefacts introduced by sample preparation. NGBLG and its aggregates $\left(0.1 \mathrm{mg} \mathrm{mL}^{-1}\right)$ were adjusted to $\mathrm{pH} 7.0$ and $\mathrm{pH} 4.0$ with $1 \mathrm{M}$ $\mathrm{NaOH}$ and $1 \mathrm{M} \mathrm{HCl}$, respectively. Then the samples were placed in a small dish, and let stand for $1 \mathrm{~h}$. A freshly cleaved mica sheet was pinched with a small tweezers to touch the air-water interface of the sample solutions and immediately removed again. The mica was then dipped into ethanol for phase exchange and removal of any unabsorbed material before slowly drying in ambient environment. The lower surface tension of ethanol could prevent the formation of artefacts during drying. Note that a strong binding of the protein and protein aggregates to the mica substrate is necessary for successful transfer. For this reason, the negatively charged mica was modified by treatment using (3-aminopropyl)triethoxysilane to carry positive charges, when depositing the samples at $\mathrm{pH}$ 7.0. No surface modification was needed for sample preparation at $\mathrm{pH}$ 4.0.

\section{Statistical analysis}

Three independent measurements were performed on each sample and all data were expressed as means. The data processing was performed using Origin 8 and Excel 2013. Statistical analysis was performed using SPSS 19.0 software, and the significance was established at $p<0.05$.

\section{Results and discussion}

\section{Size and morphology of NGBLG and its aggregates}

Microstructures of NGBLG, BLGNPs and BLGFs by TEM are shown in Fig. 1A, B and C, respectively. Fig. 1D-F show the particle size distribution of NGBLG and its aggregates obtained by Zetasizer Nano-ZS apparatus and imaging analysis using Fiber App. ${ }^{42}$ It can be seen from Fig. $1 A$ and $D$ that the particle size of NGBLG was about $6 \mathrm{~nm}$ with uniform distribution. BLGNPs showed a particle size distribution around $180 \mathrm{~nm}$ from Fig. 1B, while the most probable particle size was $350 \mathrm{~nm}$ in Fig. $1 \mathrm{E}$. The reason of difference was that the sample observed under TEM was in dry state, whereas the 350 $\mathrm{nm}$ by the measurement from Zetasizer Nano-ZS apparatus was in hydrated state. Fig. 1C shows that the lengths of the BLGFs after freeze drying were much shorter, which were mainly populated between 500-700 nm from Fiber App (Fig. 1F). ${ }^{42}$ In summary, it is confirmed that NGBLG and its aggregates with different particle sizes and shapes were prepared.

\section{Comparison of zeta potential and surface hydrophobicity of NGBLG and its aggregates}

When the net charge of NGBLG and its aggregates was equal to zero, the pHs of the NGBLG and its aggregates were in descending order (Fig. 2A): BLGFs ( $\mathrm{pH} 4.9$ ), BLGNPs ( $\mathrm{pH} 4.7)$ and NGBLG (pH 4.64). It indicated that as the structure of NGBLG unfolded, the charged amino acids in the molecule were exposed during the formation of aggregates by heating NGBLG, so the surface charge increased. The surface hydrophobicityindex (SO) of NGBLG and its aggregates showed a strong $\mathrm{pH}$ dependence (Fig. 2B). The value of $\mathrm{SO}$ at $\mathrm{pH} 4.0$ was much greater than that at $\mathrm{pH} 7.0$. At $\mathrm{pH} 7.0$, the order of SO was: BLGFs $(S 0=496)>B L G N P s(S O=277)>N G B L G(S O=99)$. When $\mathrm{pH}$ was 4.0, the order of SO was: BLGNPs $(S 0=3827)>B L G F s(S O=3196)>N G B L G(S O=1926)$. Previous papers 
reported that there was a strong increase in the surface hydrophobicity of protein aggregates, especially at $\mathrm{pH} 4 \cdot 0 .{ }^{24,43,44}$ Since the thermal treatment led to an increase in surface hydrophobicity due to exposure of more hydrophobic groups resulting from partial unfolding of the protein molecule.

\section{Foaming properties of NGBLG and its aggregates}

NGBLG and its aggregates showed different foaming properties at different pHs. At pH 7.0 (Fig. 3A), the foam height of NGBLG and BLGNPs decreased rapidly after $200 \mathrm{~s}$, while that of BLGFs began to decrease significantly after 1500 s. At pH 4.0 (Fig. 3B), the foam height of NGBLG and BLGNPs decreased rapidly after $500 \mathrm{~s}$ whereas BLGFs was very stable up to $4000 \mathrm{~s}$. The decay rates of the three were as follows: BLGNPs > NGBLG > BLGFs. The degree of decay in foam height indicated that the foam stability of NGBLG and its aggregates at $\mathrm{pH} 4.0$ was greater than at $\mathrm{pH} 7.0$, which can be seen from Fig. 3C. The stability of the foam was represented by the halflife $\left(t_{1 / 2}\right)$ at which the foam height dropped to the half of the initial value. At pH 7.0, the order of half-lives was: BLGFs ( $\mathrm{t}_{1 / 2}$ $=6704 \mathrm{~s})>\operatorname{NGBLG}\left(t_{1 / 2}=1320 \mathrm{~s}\right)>\operatorname{BLGNPs}\left(\mathrm{t}_{1 / 2}=501 \mathrm{~s}\right)$. At pH 4.0, the order of half-lives was: BLGFs $\left(t_{1 / 2}=9282 \mathrm{~s}\right)>N G B L G\left(t_{1 / 2}=2651 \mathrm{~s}\right)>$ BLGNPs $\left(t_{1 / 2}=2032 \mathrm{~s}\right)$. Fig. 3D shows the foaming capacity of NGBLG and its aggregates at $\mathrm{pH} 4.0$ was almost the same with at $\mathrm{pH}$ 7.0.

The reason for the difference in foam stability might be that the $\mathrm{pH} 4.0$ was close to the isoelectric point of NGBLG and its aggregates, thus the electrostatic repulsion was weak. The overall solution had a large bulk viscosity and formed a closely packed surface viscoelastic film, therefore exhibiting excellent foam stability. BLGFs and BLGNPs had high surface hydrophobicity, and the surface of the bubbles was more easily packed by BLGFs. However, BLGNPs had a larger particle size and molar mass, and the rate of adsorption to the surface of the foam was the slowest. Therefore, NGBLG and its aggregates showed different foam stability. This result was consistent with the previous reports. ${ }^{5,25,45}$

\section{Foam structure of NGBLG and its aggregates}

The foam height was different at different time periods, and the foam structure exhibited was also diverse. The foam structures of NGBLG and its aggregates observed by a CCD camera at $\mathrm{pH} 7.0$ and $\mathrm{pH} 4.0$ with the lapse of time are shown in Fig. $4 \mathrm{~A}$ and $\mathrm{B}$.

Since the foaming capacity of NGBLG and its aggregates was similar, the samples stopped bubbling after around $30 \mathrm{~s}$, as can be seen from the Fig. 4 . In each sample, bubbles at $30 \mathrm{~s}$ were relatively small and the distribution was relatively uniform except for BLGNPs at pH 7.0. With the lapse of time, the foam drainage increased and coalescence occurred. A significant difference in the foam structure of NGBLG and its aggregates at $\mathrm{pH} 7.0$ was recognised at $200 \mathrm{~s}$, while the foam structure of NGBLG and its aggregates at $\mathrm{pH} 4.0$ showed significant difference only after $3000 \mathrm{~s}$. Microstructure observation once again showed that the foam stabilisation of BLGFs was higher than that of NGBLG and BLGNPs.

\section{Emulsifying properties of NGBLG and its aggregates during storage}

The emulsification properties of NGBLG and its aggregates were al so compared using a model oil-inwater emulsion containing $1 \mathrm{mg} \mathrm{mL}^{-1} \mathrm{NGBLG}$ (or BLGNPs or BLGFs) and $150 \mathrm{mg} \mathrm{mL}^{-1} \mathrm{MCT}$. The change of droplet size of emulsion stabilised by NGBLG and its aggregates is displayed as a function of storage time in Fig. 5. 
Fresh emulsions prepared with NGBLG or BLGFs had almost identical $d_{43}$ at pH 7.0 in Fig. 5A, and their sizes $\left(d_{43}\right)$ did not change much during storage up to 90 days. However, the $d_{43}$ of the BLGNPs emulsion increased slightly during the storage, which indicated that the electrostatic repulsion force was not enough to maintain the stability of emulsion. The particle sizes of the emulsions of NGBLG and its aggregates at $\mathrm{pH} 4.0$ are shown in Fig. 5B. It can be seen that the temporal changes in the particle size of NGBLG and its aggregates at $\mathrm{pH} 4.0$ were larger than those at $\mathrm{pH}$ 7.0. The particle size of NGBLG and BLGFs emulsions changed from 10 to $40 \mu \mathrm{m}$ and from 13 to $65 \mu \mathrm{m}$, respectively. The particle size of BLGNPs emulsion increased more strongly from $44 \mu \mathrm{m}$ to $176 \mu \mathrm{m}$. The reason for the difference in the particle size of the emulsions of NGBLG and its aggregates at different pHs might be that NGBLG and its aggregates had a higher negative charge at $\mathrm{pH}$ 7.0. The high electrostatic repulsion between emulsion droplets was beneficial to the stability of emulsion. At pH 4.0, the net charge of NGBLG and its aggregates was low, and the $\mathrm{pH}$ was close to the isoelectric point of the protein. The interaction between protein and protein was enhanced, and flocculation occurred between the emulsion droplets.

\section{Microstructure of emulsion}

The microstructure of emulsions immediately after preparation and after 90 days storage was studied by optical microscopy. At pH 7.0 (Fig. 6A), the fresh emulsion droplets prepared by NGBLG and its aggregates were evenly distributed and only slightly aggregated after storage for 90 days. At pH 4.0 (Fig. 6B), the fresh emulsion droplets of NGBLG and its aggregates initially had a slight aggregation. After 90 days of storage, the droplet size became larger and a large amount of aggregation occurred. The emulsions which were prepared by BLGFs and NGBLG had finer particle size and better stability, and this phenomenon was related to the amount of charge. This is consistent with the description of the size changes above.

\section{Surface adsorption behavior}

Fig. 7 shows the relationship between surface pressure $(\pi)$ with time and surface dilatational modulus (E) with surface pressure $(\pi)$ of NGBLG and its aggregates at the air-water interface. As shown in Fig. 7A and $B$, the surface pressure of NGBLG and its aggregates increased steeply within the first $1000 \mathrm{~s}$, and then tended to approach to a constant value. The initial increase seemed to be more rapid at $\mathrm{pH} 4.0$ than that at $\mathrm{pH}$ 7.0. This was presumably related to a higher hydrophobicity of the protein and protein aggregates at $\mathrm{pH} 4.0$, which led to a faster interfacial adsorption kinetices. ${ }^{46}$ Among the three samples, the BLGFs exhibited the largest surface pressure value, and the surface pressure of BLGNPs was the smallest at both $\mathrm{pH} 7.0$ and $\mathrm{pH}$ 4.0. The possible causes were not only related to surface hydrophobicity, but also to the different size and molar mass of NGBLG and its aggregates. Some studies showed that BLGFs exhibited a faster interfacial adsorption than NGBLG, ${ }^{27}$ and similar phenomenon was observed for other proteins. ${ }^{47}$ However, regarding BLGNPs, they were found to have slower interfacial adsorption compared with nonaggregated NGBLG, and the adsorption rate decreased with increasing size. ${ }^{25}$ Our results are therefore in consistence with literature reports. The corresponding surface dilatational modulus changed with surface pressure as shown in Fig. 7C and D. At pH 7.0 (Fig. 7C), surface dilatational modulus of BLGFs at the air-water interface reached about $61 \mathrm{mN} \mathrm{m}^{-1}$, which was higher than those of NGBLG $\left(41 \mathrm{mN} \mathrm{m}^{-1}\right)$ and BLGNPs $\left(37 \mathrm{mN} \mathrm{m}^{-1}\right.$ ). At pH 4.0 (Fig. 7D), the maximum value of dilatational modulus of BLGFs at the air-water interface was approximately $67 \mathrm{mN} \mathrm{m}^{-1}$, which was higher than those of NGBLG (47 mN $\left.\mathrm{m}^{-1}\right)$ and BLGNPs $\left(44 \mathrm{mN} \mathrm{m}^{-1}\right)$. Surface dilatational modulus of NGBLG and its aggregates at $\mathrm{pH} 4.0$ was greater than that at $\mathrm{pH} 7.0$, indicating that the viscoelastic surface films of NGBLG and its aggregates were stronger at $\mathrm{pH}$ 4.0. It was found that the surface dilatational modulus increased when the $\mathrm{pH}$ of protein solution approached to its isoelectric point, which was consistent with the 
results of this study. ${ }^{48}$ This behaviour was attributed to the relaxation mechanism at the air-water interface, which included the dynamic exchange behaviour of molecules between the surface and bulk phases and their structural rearrangement after adsorption on the surface. ${ }^{49,50}$ In addition, a higher zeta potential caused a strong electrostatic repulsion between NGBLG and its aggregates at the interface at $\mathrm{pH} 7.0$, resulting in the bubbles not being densely packed by NGBLG and its aggregates. Therefore, NGBLG and its aggregates at $\mathrm{pH} 7.0$ had a lower foam stability. The foam stability can be explained by the magnitude of surface dilatational modulus and the amount of charge carried by NGBLG and its aggregates. The above interface mechanics results once again demonstrate the foaming properties of NGBLG and its aggregates.

\section{Interfacial microstructure}

The adsorption morphologies of NGBLGand its aggregates at the air-water interface were observed by AFM. At both pH 7.0 and pH 4.0, NGBLG (Fig. 8A and D) formed a relatively more homogenous interfacial adsorption film. The interfacial structure formed by BLGFs (Fig. $8 \mathrm{C}$ and F) exhibited a continuous network feature, while that of BLGNPs (Fig. 8B and E) was rather dispersed. Comparison between $\mathrm{pH} 7.0$ and $\mathrm{pH} 4.0$ revealed a higher degree of aggregation at $\mathrm{pH} 4.0$, which should be

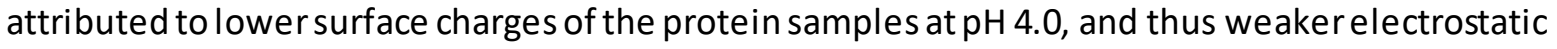
repulsion. The interfacial microstructures observed by AFM seem to support the interfacial mechanical properties as discussed above.

Through self-assembly, NGBLG formed semiflexible BLGFs with a high aspect ratio and surface hydrophobicity. BLGFs could quickly adsorb to the interface and formed a tight network structure at the air-water interface. ${ }^{27}$ As a globular protein, NGBLG had a small molar mass and a large specific surface area. Upon interfacial adsorption, NGBLG molecules unfolded and interacted each other at the air-water interface to form an elasticinterfacial film with a high dilatational modulus..$^{48}$

Additionally, NGBLG could form BLGNPs with high surface hydrophobicity in an irreversible manner. Due to its large particle size, high molar mass, and the smallest specific surface area, the adsorption rate of BLGNPs was the slowest at the air-water interface, and BLGNPs adsorption capacity was lower than NGBLG or BLGFs, resulting in a less tight interfacial film and the lowest surface dilatational modulus. ${ }^{25}$ The difference between $\mathrm{pH} 7.0$ and 4.0 was mainly due to the fact that $\mathrm{pH}$ 4.0 was close to the isoelectric point, and the low net charge minimized the electrostatic repulsion of NGBLG and its aggregates to the extent that the protein-protein interaction became attractive, and aggregation occurred between the protein species. A dense multi-layer network structure with high interfacial elasticity was formed at the interface. The thick and disordered adsorption layers led to the highest foam stability. The higher dilatational modulus helped to prevent foam drainage and coarsening, and increased the mechanical strength of the foam. At pH 7.0, a high negative charge caused a strong electrostatic repulsion to maintain stability between the droplets, but electrostatic repulsion between the charged NGBLG and its aggregates prevented the formation of multiple layers at the interface. Therefore, the interfacial dilatational modulus and the foam stability decreased as the repulsion between NGBLG and its aggregates increased. Engelhardt et al. studied the effect of $\mathrm{pH}$ on the molecular structure of $\beta$-lactogl obul in and the resulting air-water interface, in relation to foam rheology. ${ }^{45}$ Similar observations were reported.

\section{Conclusions}

The aim of this study was to systematically compare the foaming and emulsifying properties of NGBLG and its aggregates (BLGNPs and BLGFs). We clearly demonstrated the difference in foaming and emulsifying properties of NGBLG and its aggregates at different $\mathrm{pHs}$. It was found that NGBLG and its aggregates had better emulsion stability at $\mathrm{pH}$ 7.0, but their foam stability was better at $\mathrm{pH}$ 4.0. The foam and emulsion stability of NGBLG and its aggregates were in the order of: 
BLGFs > NGBLG > BLGNPs, indicating that heating NGBLG to prepare BLGFs rather than BLGNPs can effectively improve the foaming and emulsifying properties of the protein. Therefore, BLGFs may be used as a promising foaming and emulsifying agents in the food industry.

\section{Conflicts of interest}

There are no conflicts to declare.

\section{Acknowledgements}

The research was supported by the National Natural Science Foundation of China (31671811) and the Science and Technology Commission of Shanghai Municipality (No. 18JC1410801).

\section{References}

$1 \mathrm{E}$. A. Foegeding and J. P. Davis, Food protein functionality: A comprehensive approach, Food Hydrocolloids, 2011, 25, 1853-1864.

2 S. Petursson, E. A. Decker and D. J. Mcclements, Stabilization of oil-in-water emulsions by cod protein extracts, J. Agric. Food Chem., 2004, 52, 3996-4001.

3 P. J. Wilde, A. R. Mackie, F. A. Husband, P. Gunning and V. J. Morris, Proteins and emulsifiers at liquid interfaces, Adv. Colloid Interface Sci., 2004, 108, 63-71.

4 E. A. Foegeding, P. J. Luck and J. P. Davis, Factors determining the physical properties of protein foams, Food Hydrocolloids, 2006, 20, 284-292.

5 T. Nicolai, M. Britten and C. Schmitt, $\beta$-Lactoglobulin and WPI aggregates: Formation, structure and applications, Food Hydrocolloids, 2011, 25, 1945-1962.

6 J. P. Simons, M. McClenaghan and A. J. Clark, Alteration of the quality of milk by expression of sheep $\beta$-lactoglobulin in transgenic mice, Nature, 1987, 328, 530-532.

7 M. Z. Papiz, L. Sawyer, E. E. Eliopoulos, A. C. T. North, J. B. C. Findlay, R. Sivaprasadarao, T. A. Jones, M. E. Newcomer and P. J. Kraulis, The structure of beta-lactoglobulin and its similarity to plasma retinol-binding protein, Nature, 1986, 324, 383-385.

8 B. Y. Qin, M. C. Bewley, L. K. Creamer, H. M. Baker, E. N. Baker and G. B. Jameson, Structural basis of the Tanford transition of bovine $\beta$-lactoglobulin, Biochemistry, 1998, 37, 14014-14023.

9 S. P. F. M. Roefs and K. G. De Kruif, A model for the denaturation and aggregation of $\beta$ lactoglobulin, Eur. J. Biochem., 1994, 226, 883-889.

10 G. A. Manderson, M. J. Hardman and L. K. Creamer, Effect of heat treatment on the conformation and aggregation of $\beta$-lactoglobulin A, B, and C, J. Agric. Food Chem., 1998, 46, 5052-5061.

11 E. V. Der Linden and P. Venema, Self-assembly and aggregation of proteins, Curr. Opin. Colloid Interface Sci., 2007, 12, 158-165. 
$12 \mathrm{H}$. Zhu and S. Damodaran, Heat-induced conformational changes in whey protein isolate and its relation to foaming properties, J. Agric. Food Chem., 1994, 42, 846-855.

$13 \mathrm{H}$. Zhu and S. Damodaran, Effects of calcium and magnesium ions on aggregation of whey protein isolate and its effect on foaming properties, J. Agric. Food Chem., 1994, 42, 856-862.

$14 \mathrm{~S}$. Mehalebi, T. Nicolai and D. Durand, Light scattering study of heat-denatured globular protein aggregates, Int. J. Biol. Macromol., 2008, 43, 129-135.

15 G. M. Kavanagh, A. H. Clark and S. B. Rossmurphy, Heatinduced gelation of globular proteins: Part 3. Molecular studies on low pH beta-lactogl obulin gels, Int. J. Biol. Macromol., 2000, 28, 41-50.

16 A. M. Etorki, M. Gao, R. Sadeghi, L. F. Maldonado-Mejia and J. L. Kokini, Effects of desolvating agent types, ratios, and temperature on size and nanostructure of nanoparticles from $\alpha$-Lactalbumin and ovalbumin, J. Food Sci., 2016, 81, E2511-E2520.

17 D. Weaire and R. Phelan, The physics of foam, J. Phys.: Condens. Matter, 1996, 8, 9519-9524.

18 M. Liszka-Skoczylas, A. Ptaszek and D. Żmudziński, The effect of hydrocolloids on producing stable foams based on the whey protein concentrate (WPC), J. Food Eng., 2014, 129, 1-11.

19 J. N. Miquelim, S. C. S. Lannes and R. Mezzenga, pH Influence on the stability of foams with protein-polysaccharide complexes at their interfaces, Food Hydrocolloids, 2010, 24, 398-405.

20 G. Yampolskaya and D. Platikanov, Proteins at fluid interfaces: Adsorption layers and thin liquid films, Adv. Colloid Interface Sci., 2006, 128, 159-183.

21 L. G. Cascão Pereira, C. Johansson, C. J. Radke and H. W. Blanch, Surface forces and drainage kinetics of proteinstabilized aqueous films, Langmuir, 2003, 19, 7503-7513.

22 B. Rullier, M. A. V. Axelos, D. Langevin and B. Novales, $\beta$-Lactoglobulin aggregates in foam films: Effect of the concentration and size of the protein aggregates, J. Colloid Interface Sci., 2010, 343, 330-337.

23 L. G. Phillips, W. Schulman and J. E. Kinsella, pH and heat treatment effects on foaming of whey protein isolate, J. Food Sci., 1990, 55, 1116-1119.

24 D. A. Kim, M. Cornec and G. Narsimhan, Effect of thermal treatment on interfacial properties of $\beta$ lactoglobulin, J. Colloid Interface Sci., 2005, 285, 100-109.

25 B. Rullier, B. Novales and M. A. V. Axelos, Effect of protein aggregates on foaming properties of $\beta$ lactoglobulin, Colloids Surf., A, 2008, 330, 96-102.

26 C. Kotsmar, D. O. Grigoriev, F. Xu, E. V. Aksenenko, V. B. Fainerman, M. E. Leserand R. Miller, Equilibrium of adsorption of mixed milk protein/surfactant solutions at the water/air interface, Langmuir, 2008, 24, 13977-13984.

27 J.-M. Jung, D. Z. Gunes and R. Mezzenga, Interfacial activity and interfacial shear rheology of native $\beta$-lactoglobulin monomers and their heat-induced fibers, Langmuir, 2010, 26, 15366-15375. 
28 D. Peng, J. Yang, J. Li, C. Tang and B. Li, Foams stabilized by $\beta$-lactoglobul in amyloid fibrils: Effect of pH, J. Agric. Food Chem., 2017, 65, 10658-10665.

29 A. Medrano, C. Abirached, A. C. Araujo, L. A. Panizzolo, P. Moyna and M. C. Añón, Correlation of average hydropho-bicity, water/air interface surface rheological properties and foaming properties of proteins, Food Sci. Technol. Int., 2012, 18, 187-193.

30 P. Walstra, Principles of foam formation and stability, in Foams: Physics, chemistry and structure, ed. A. J. Wilson, Springer-Verlag, London, 1989, pp. 1-15.

31 X. Li, Y. Fang, S. Al-Assaf, G. O. Phillips and F. Jiang, Complexation of bovine serum albumin and sugar beet pectin: Stabilising oil-in-water emulsions, J. Colloid Interface Sci., 2012, 388, 103-111.

32 E. Bouyer, G. Mekhloufi, I. Le Potier, T. D. F. De Kerdaniel, J.-L. Grossiord, V. Rosilio and F. Agnely, Stabilization mechanism of oil-in-water emulsions by $\beta$-lactogl obulin and gum arabic, J. Colloid Interface Sci., 2011, 354, 467-477.

33 E. Dickinson, Protein-stabilized emulsions, J. Food Eng., 1994, 22, 59-74.

$34 \mathrm{M}$. A. Bos and T. Van Vliet, Interfacial rheological properties of adsorbed protein layers and surfactants: A review, Adv. Colloid Interface Sci., 2001, 91, 437-471.

35 D. J. Mcclements, Protein-stabilized emulsions, Curr. Opin. Colloid Interface Sci., 2004, 9, 305313.

36 Y. Serfert, C. Lamprecht, C. P. Tan, J. K. Keppler, E. Appel, F. J. Rossiermiranda, K. Schroen, R. M. Boom, S. N. Gorb and C. Selhuberunkel, Characterisation and use of $\beta$-lactoglobulin fibrils for microencapsulation of lipophilic ingredients and oxidative stability thereof, J. Food Eng., 2014, 143, 53-61.

37 J. C. Knudsen, L. H. Ogendal and L. H. Skibsted, Droplet surface properties and rheology of concentrated oil in water emulsions stabilized by heat-modified $\beta$-lactoglobulin B, Langmuir, 2008, 24, 2603-2610.

38 R. Aschaffenburg and J. Drewry, Improved method for the preparation of crystalline $\beta$ lactoglobulin and $\alpha$-lactalbumin from cow's milk, Biochem. J., 1957, 65, 273-277.

$39 \mathrm{~J}$. Toro-Sierra, A. Tolkach and U. Kulozik, Fractionation of $\alpha$-lactalbumin and $\beta$-lactoglobulin from whey protein isolate using selective thermal aggregation, an optimized membrane separation procedure and resolubilization techniques at pilot plant scale, Food Bioprocess Technol., 2013, 6, 1032-1043.

$40 \mathrm{~A}$. Kato and S. Nakai, Hydrophobicity determined by a fluorescence probe method and its correlation with surface properties of proteins, Biochim. Biophys. Acta, 1980, 624, 13-20.

$41 \mathrm{~S}$. Jordens, L. Isa, I. Usov and R. Mezzenga, Non-equilibrium nature of two-dimensional isotropic and nematic coexistence in amyloid fibrils at liquid interfaces, Nat. Commun., 2013, 4, 1917.

42 I. Usov and R. Mezzenga, FiberApp: An open-source software for tracking and analyzing polymers, filaments, biomacromolecules, and fibrous objects, Macromolecules, 2015, 48, 1269-1280. 
$43 \mathrm{~S}$. Cairoli, S. Iametti and F. Bonomi, Reversible and irreversible modifications of $\beta$-lactoglobulin upon exposure to heat, J. Protein Chem., 1994, 13, 347-354.

44 M. Shimizu, M. Saito and K. Yamauchi, Emulsifying and structural properties of $\beta$-lactoglobulin at different pHs, Agric. Biol. Chem., 1985, 49, 189-194.

45 K. Engelhardt, M. Lexis, G. Gochev, C. Konnerth, R. Miller, N. Willenbacher, W. Peukert and B. Braunschweig, pHeffects on the molecular structure of $\beta$-lactoglobulin modified air-water interfaces and its impact on foam rheology, Langmuir, 2013, 29, 11646-11655.

46 S. Damodaran and K. B. Song, Kinetics of adsorption of proteins at interfaces: Role of protein conformation in diffusional adsorption, Biochim. Biophys. Acta, 1988, 954, 253-264.

47 Z. Wan, X. Yang and L. M. C. Sagis, Nonlinear surface dilatational rheology and foaming behavior of protein and protein fibrillar aggregates in the presence of natural surfactant, Langmuir, 2016, 32, 3679-3690.

48 P. A. Wierenga and H. Gruppen, New views on foams from protein solutions, Curr. Opin. Colloid Interface Sci., 2010, 15, 365-373.

49 E. M. Freer, K. S. Yim, G. G. Fuller and C. J. Radke, Shear and dilatational relaxation mechanisms of globular and flexible proteins at the hexadecane/water interface, Langmuir, 2004, 20, 10159-10167.

50 W. Jin, J. Zhu, Y. Jiang, P. Shao, B. Li and Q. Huang, Gelatin-based nanocomplex-stabilized pickering emulsions: Regulating droplet size and wettability through assembly with glucomannan, $J$. Agric. Food Chem., 2017, 65, 1401-1409. 


\section{Figure Captions}

Fig. 1 TEM micrographs and particle size distribution of NGBLG and its aggregates: NGBLG (A and D), BLGNPs (B and E) and BLGFs ( $C$ and F). Scale bar: $0.5 \mu \mathrm{m}$.

Fig. 2 Zeta potential $\zeta$ as a function of $\mathrm{pH}$ for NGBLG and its aggregates $(A)$ and the surface hydrophobicity index of NGBLG and its aggregates at $\mathrm{pH} 7.0$ and $\mathrm{pH} 4.0$ (B).

Fig. 3 Time dependence of the foam height of NGBLG and its aggregates $\left(1 \mathrm{mg} \mathrm{mL}^{-1}\right)$ at $\mathrm{pH} 7.0$ (A) and $\mathrm{pH} 4.0(\mathrm{~B})$, foam half-life time (C) and foaming capacity (D) of NGBLG and its aggregates (1 mg $\mathrm{mL}^{-1}$ ) at different $\mathrm{pHs}$. a-e in Fig. 3C/3D are significantly different at $\mathrm{p}<0.05$.

Fig. 4 Time dependence of the foam structures observed by a CCD camera at $\mathrm{pH} 7.0(\mathrm{~A})$ and $\mathrm{pH} 4.0$ (B). Solid bars in all images correspond to a length of $1 \mathrm{~mm}$.

Fig. 5 The change of droplet size of emulsion stabilised by NGBLG and its aggregates at $\mathrm{pH} 7.0$ (A) and $\mathrm{pH} 4.0$ (B) as a function of storage time.

Fig. 6 Light microscopic observation of emulsions of NGBLG and its aggregates immediately after preparation and after 90 days storage at $\mathrm{pH} 7.0$ (A) and pH 4.0 (B). Scale bar: $50 \mu \mathrm{m}$.

Fig. 7 Time evolution of the surface pressure $(\pi)$ for the adsorption of NGBLG and its aggregates ( 0.1 $\mathrm{mg} \mathrm{mL}^{-1}$ ) at $\mathrm{pH} 7.0(\mathrm{~A})$ and $\mathrm{pH} 4.0(\mathrm{~B})$ and surface dilatational modul us (E) as a function of surface pressure $(\pi)$ for NGBLG and its aggregates $\left(0.1 \mathrm{mg} \mathrm{mL}^{-1}\right)$ at $\mathrm{pH} 7.0(\mathrm{C})$ and $\mathrm{pH} 4.0$ (D) at the air-water interface.

Fig. 8 AFM images of $0.1 \mathrm{mg} \mathrm{mL}^{-1}$ NGBLG, BLGNPs, BLGFs at pH 7.0 (A-C) and pH 4.0 (D-F). Scale bar: $1.0 \mu \mathrm{m}$. 

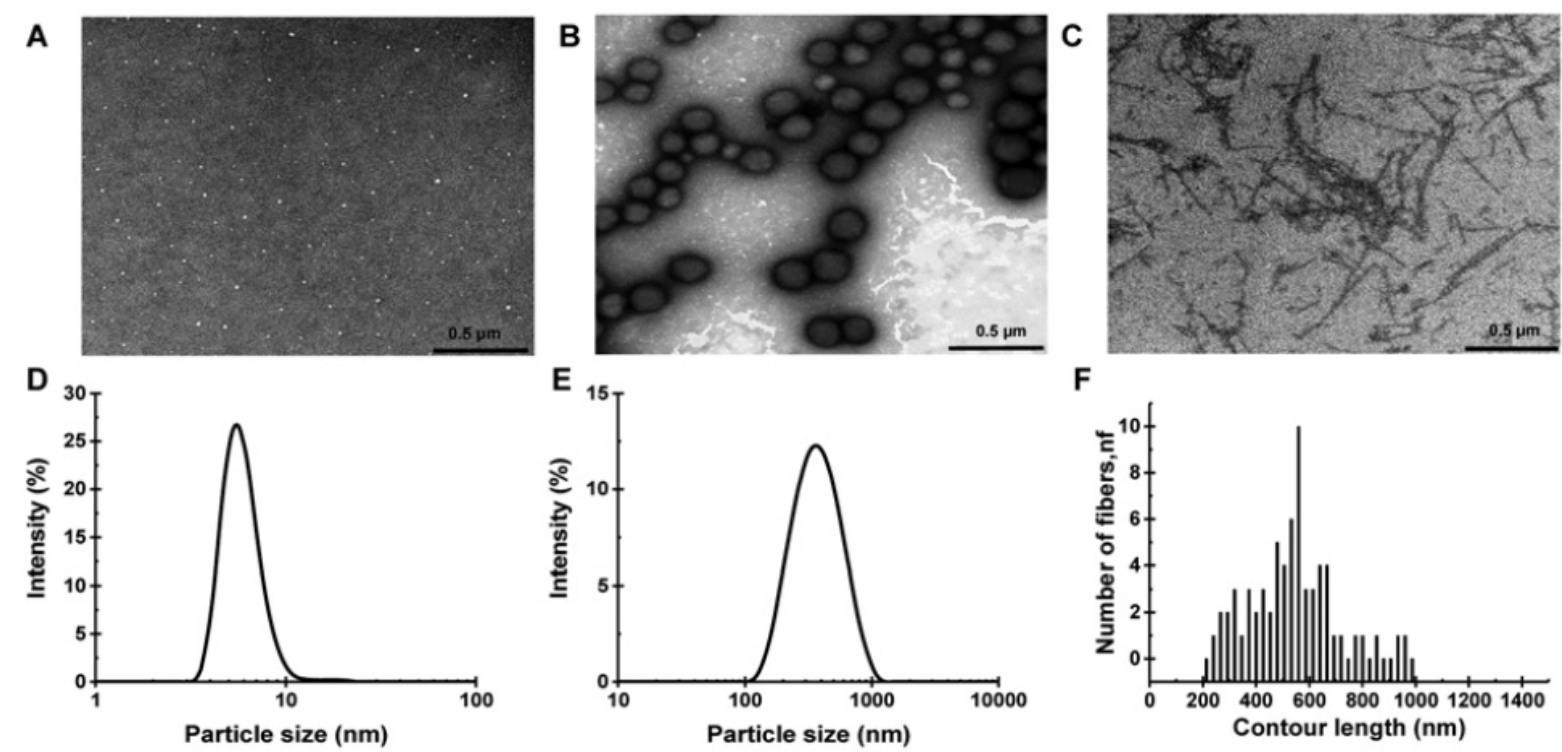

Fig. 1
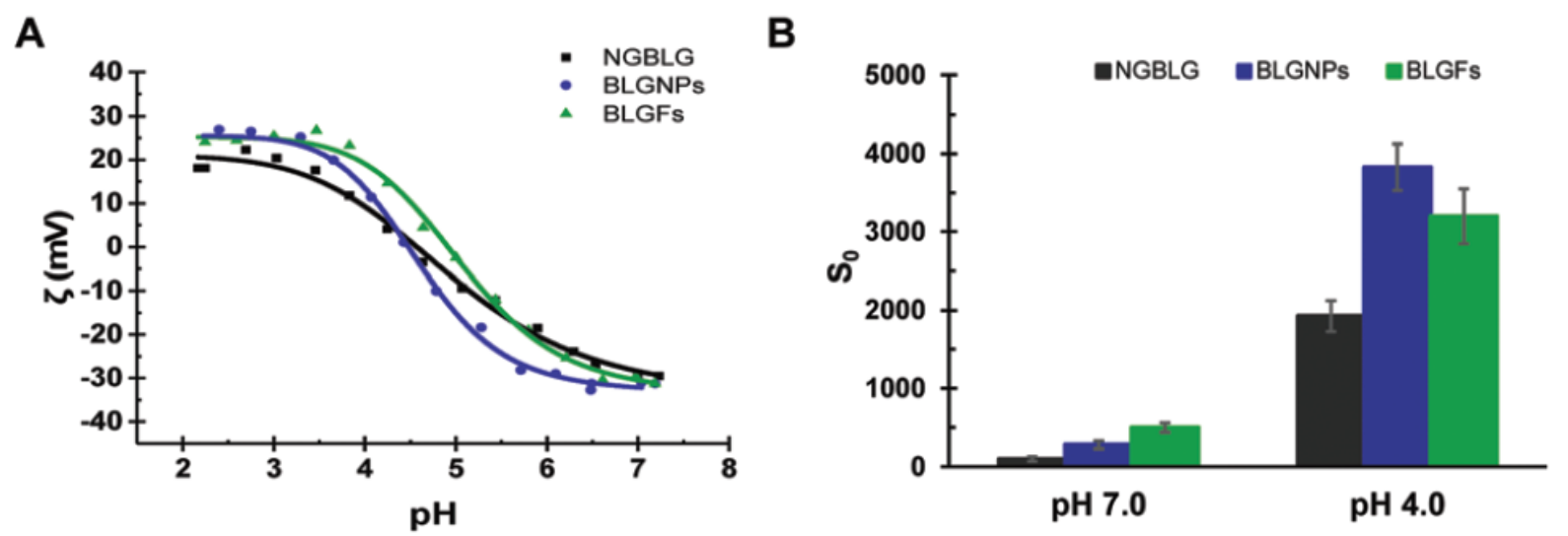

Fig. 2 

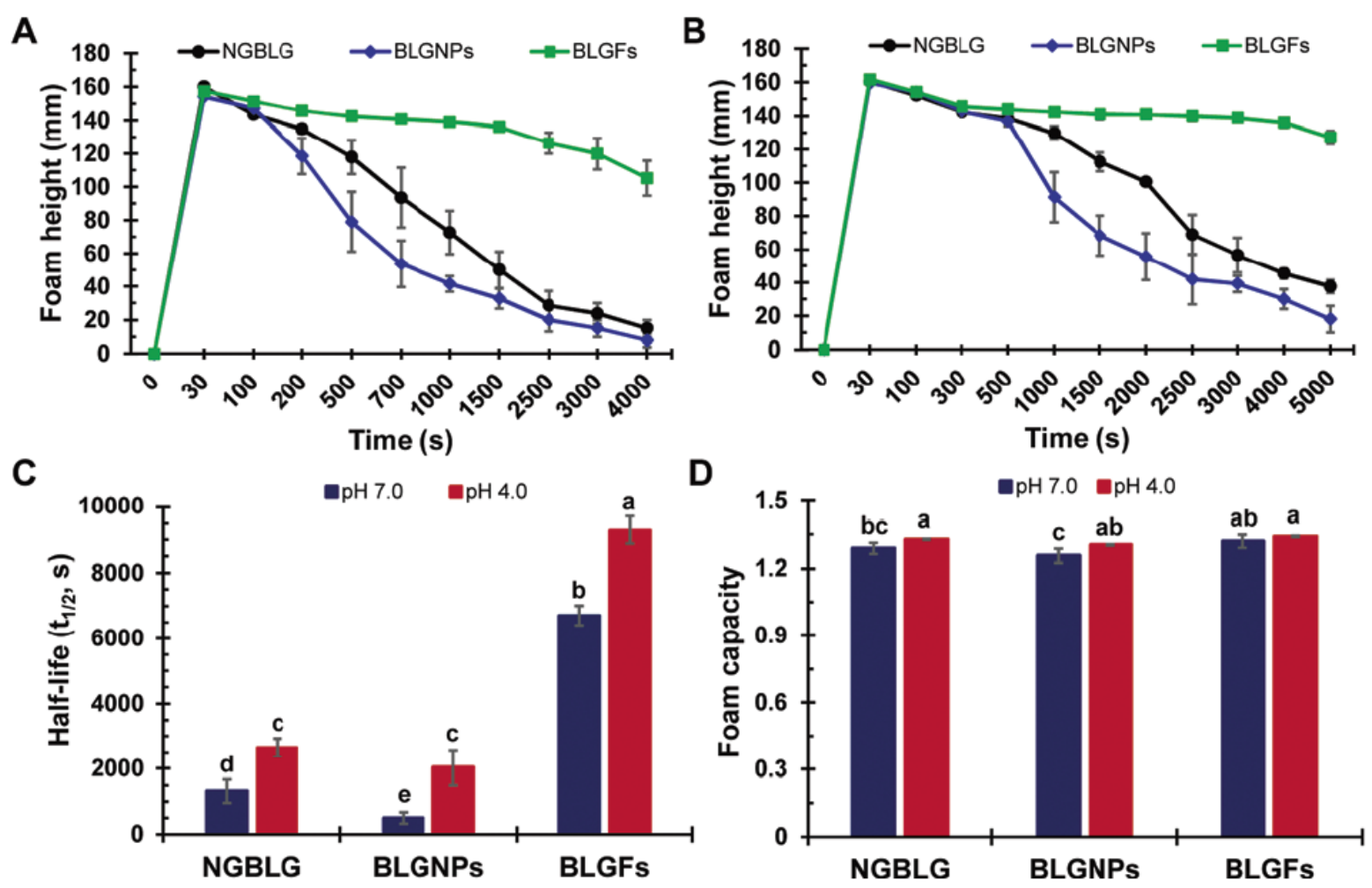

Fig. 3 


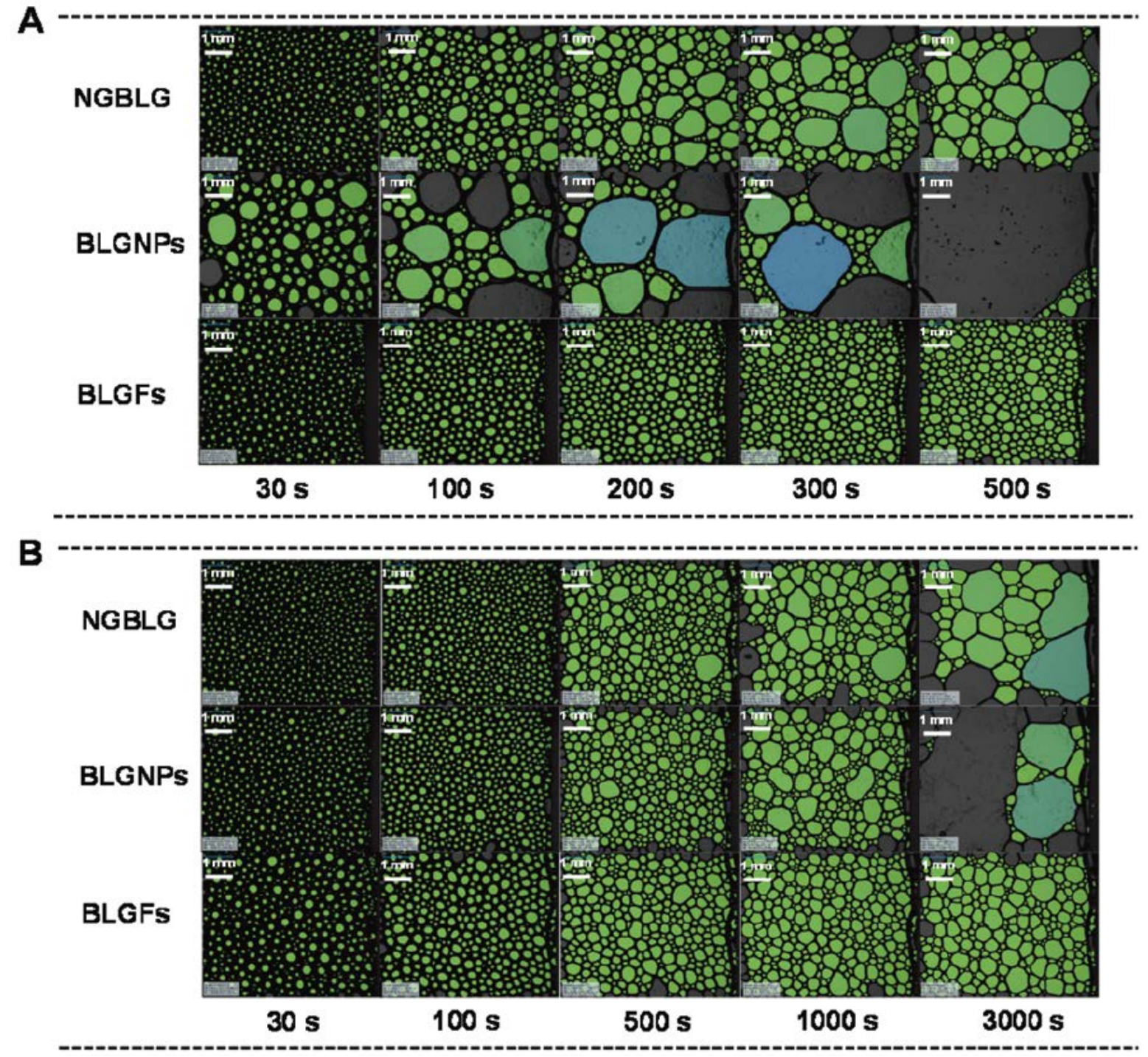

Fig. 4 

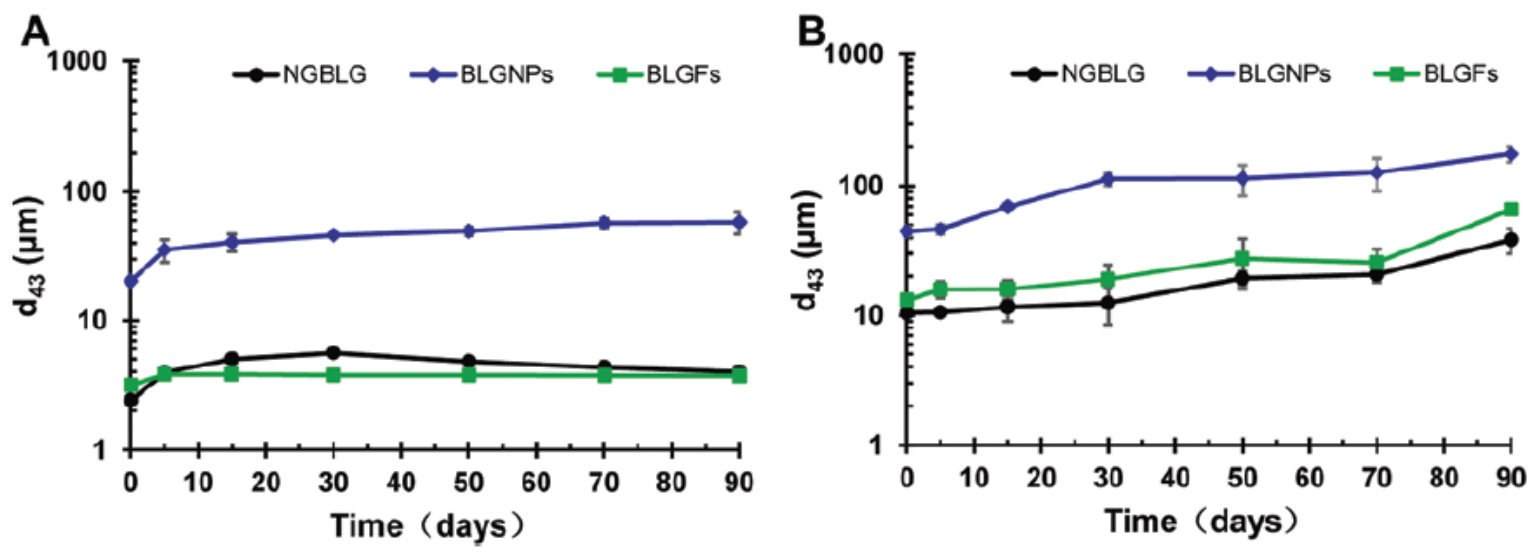

Fig. 5
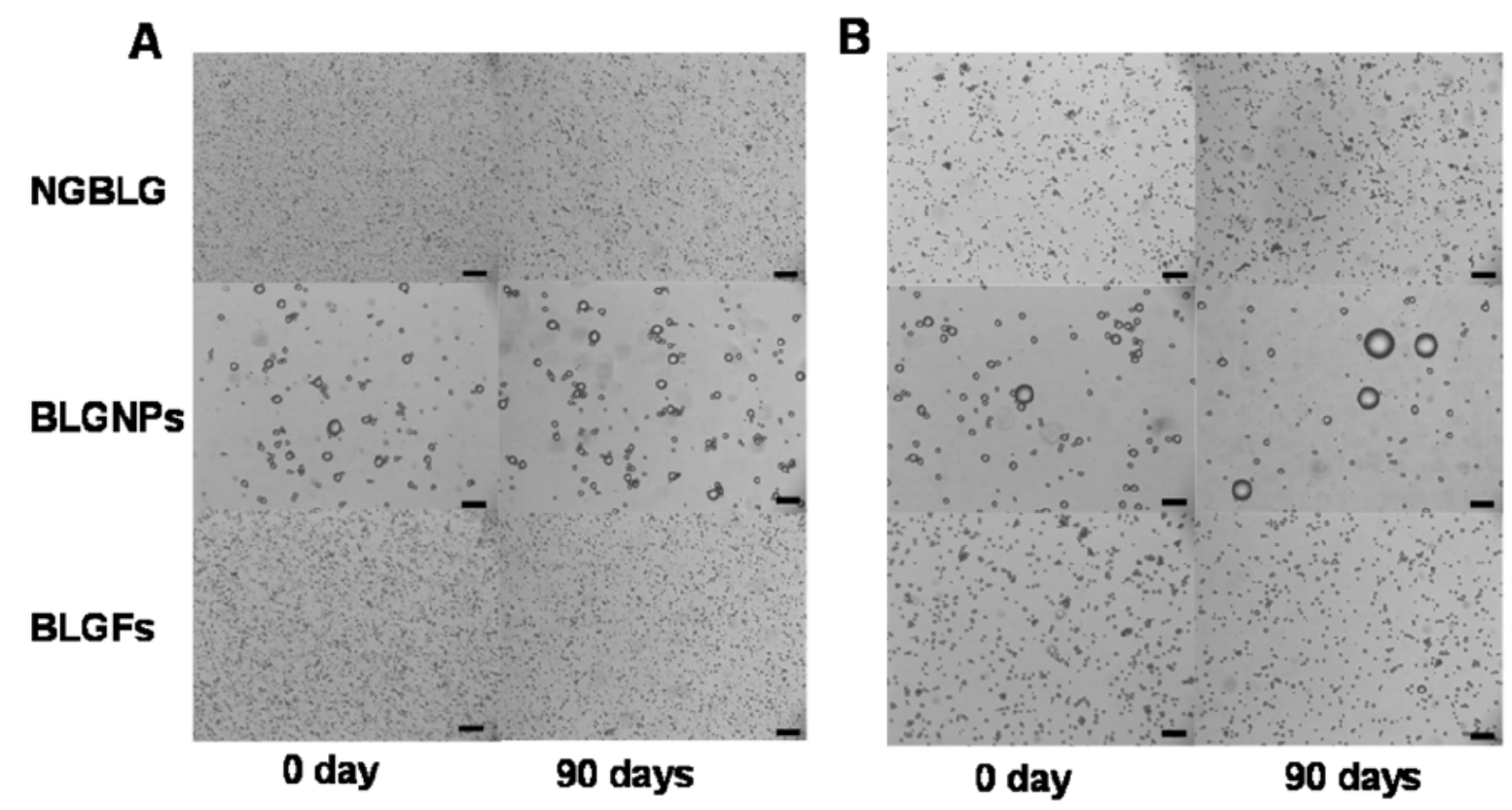

Fig. 6 


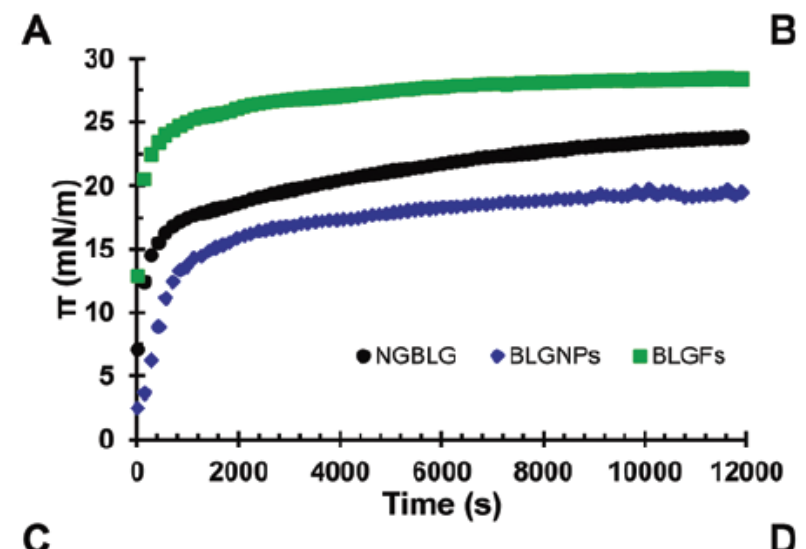

B
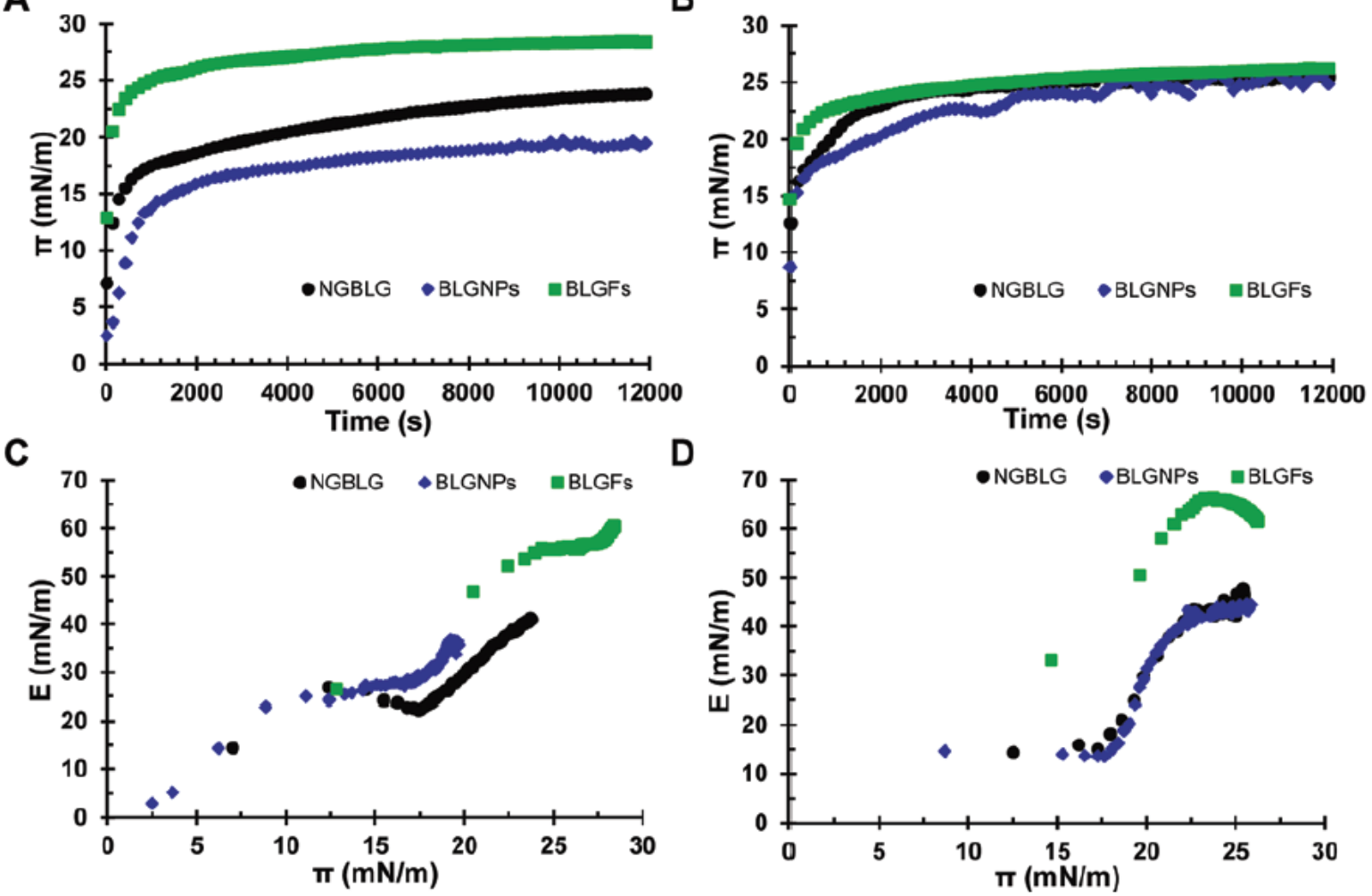

Fig. 7 


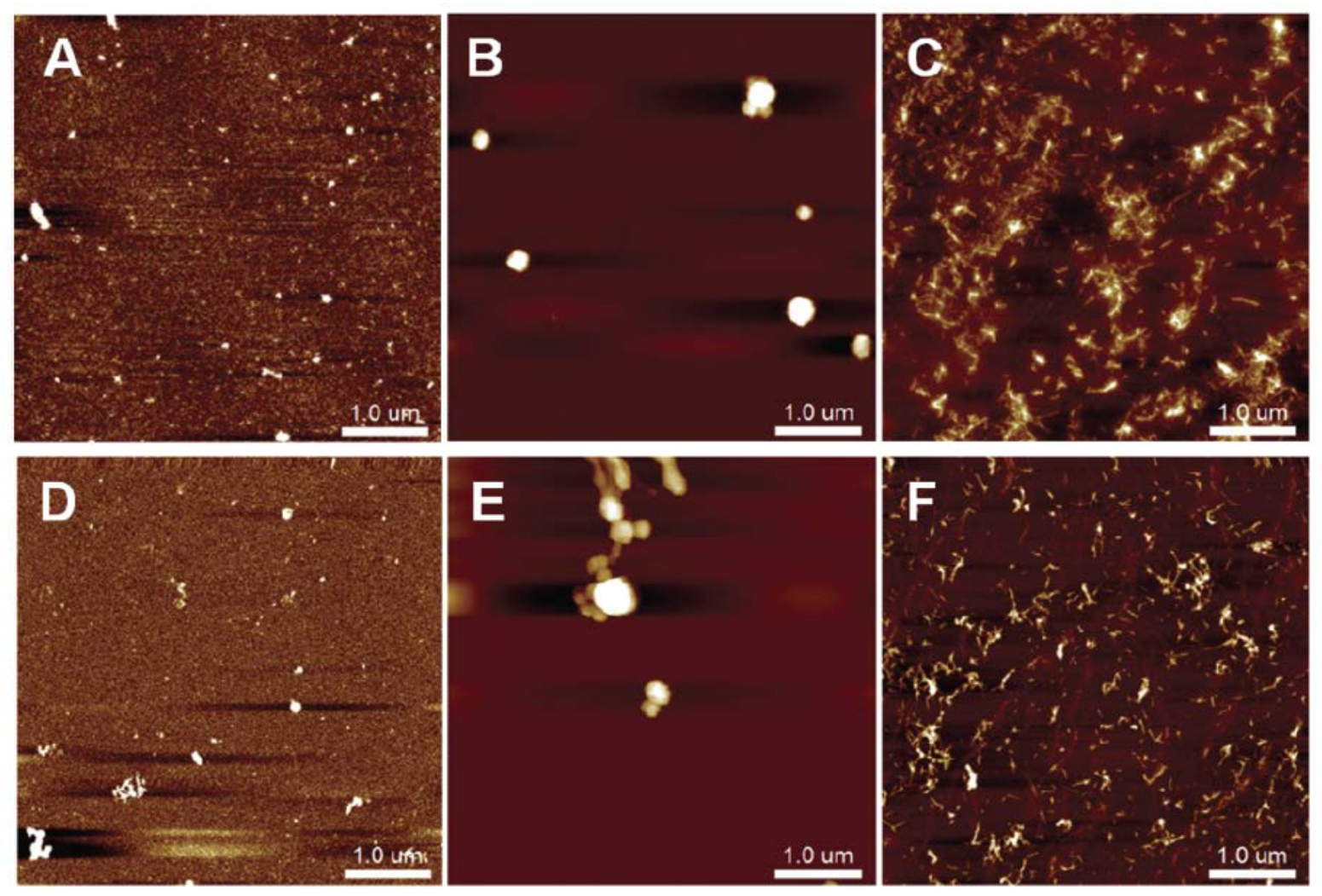

Fig. 8 